\title{
Differences in the searching behaviour of two strains of the egg parasitoid Telenomus busseolae (Hymenoptera: Scelionidae)
}

\author{
Stefano COLAZZA ${ }^{1}$ and M. Cristiana ROSI ${ }^{2}$ \\ ${ }^{1}$ Institute of Agricultural Entomology, University of Palermo, Viale delle Scienze 13, 90128, Palermo, Italy; \\ e-mail: colazza@unipa.it \\ ${ }^{2}$ Agricultural Biotechnology Department, University of Florence, P-le delle Cascine, 05121, Florence, Italy
}

Key words. Sesamia nonagrioides, Noctuidae, Telenomus busseolae, Scelionidae, egg parasitoid, semiochemicals, video tracking, strains, biological control

\begin{abstract}
Telenomus busseolae Gahan (Hymenoptera: Scelionidae) is an egg parasitoid, which is under evaluation for possible introduction into Italy as a biological control agent of the Corn Stalk Borer, Sesamia nonagrioides (Lefebvre) (Lepidoptera: Noctuidae). Two strains are being considered, one from Africa and the other from Turkey. In a series of laboratory experiments we compared their reproductive capacities, walking behaviour, and host selection behaviour mediated by the sex pheromone and body scales of the host. As reciprocal crosses between the two strains yielded female offspring, they are not reproductively isolated. The two strains were similar in both their reproductive capacity and female longevity. Females of both produced 75-90 eggs and lived on average for 6-7 days. There were differences between the two strains in walking behaviour, searching pattern and in the host location behaviour. The African strain walked faster then the Turkish strain, and showed a slower angular speed and lower turning rate. The African strain showed a significant increase in its speed of movement in response to the host's sex pheromone and a more intense local search after encountering host body scales. These results on intraspecific variability could help choosing an appropriate strain of T. busseolae for corn borer management in Italy.
\end{abstract}

\section{INTRODUCTION}

The scelionid Telenomus busseolae Gahan is a solitary egg parasitoid of several species of noctuid stemborers (Alexandri \& Tsitsipis, 1990; Sétamou \& Schulthess, 1995; Fantinou et al., 1998), and has been recorded from several African and Middle East countries and in India (Polaszek et al., 1993). In the Mediterranean basin and in West Africa the level of parasitism by $T$. busseolae is high, e.g. in Turkey Telenomus (=Platytelenomus) busseolae parasitizes $\approx 80 \%$ of the eggs of Sesamia nonagrioides (Lefebvre) (Kornosor et al., 1994); in the Republic of Benin $\approx 76 \%$ of the eggs of Sesamia calamistis (Gahan) (Sétamou \& Schulthess, 1995); in the Ivory Coast $\approx 72 \%$ of the eggs of Busseola fusca (Fuller) (Moyal, 1998). In Europe, this parasitoid has been recorded only in Greece (Polaszek et al., 1993), where it achieved similar levels of parasitism (Alexandri \& Tsitsipis, 1990).

In Italy, $S$. nonagrioides is a pest of cultivated Graminaceae (Prota, 1965; Nucifora, 1966), and newly emerged larvae are controlled mainly with chemicals. These chemicals are used in conjunction with female sex pheromone traps (Rotundo et al., 1985). Recently, the possibility of using $T$. busseolae as a biological control agent against the corn stalk borer has received more attention. In 1991 an attempt to introduce this species into Italy from Greece failed (Laudonia et al., 1991). In 1995 and 1996, respectively, specimens from Adana (Turkey) and Cotonou (Republic of Benin), were reared in isolation and identified as a separate strain sensu Diehl \& Bush (1984).

Intraspecific variability in parasitoid physiology and behaviour is well known (Ruberson et al., 1989), and comparative evaluations of strains help in the selection of potential candidates for biological control programs (Gonzalez et al., 1979; Ruberson et al., 1989). However, more studies on intraspecific variability have been done on parasitoids life history, and host selection behaviour has received less attention (Ruberson et al., 1989).

In this study, we compared the reproductive capacities and host location behaviour in term of the female wasp's response to the host sex pheromone and body scales of the corn stalk borer, of the African and Turkish strain of T. busseolae.

\section{MATERIAL AND METHODS}

Insect maintenance. Two geographically isolated strains of T. busseolae were used. The Turkish strain was established from parasitised egg masses of $S$. nonagrioides collected from maize in the region of Adana, Turkey, and the African strain from about 18 parasitised egg masses of Sesamia calamistis Hampson collected from maize fields in southern Benin. T. busseolae adults of both strains were supplied with honey-water solution and $S$. nonagrioides egg-masses in glass tubes $(16 \mathrm{ml})$. The Turkish strain and the African strain, respectively, were reared in this way for about 30 and 20 generations. The culture of $S$. nonagrioides was established from pupae collected in central Italy and reared on a diet of milled corn stalks and cobs (Giacometti, 1995). Both species were kept in the laboratory under a regime of $26 \pm 1{ }^{\circ} \mathrm{C}, 65 \pm 5 \% \mathrm{RH}$, and a photoperiod of 16L : 8D. 
TABLE 1. Reciprocal crosses between two strains of T. busseolae. Results are given as means and standard deviation. Values in a column followed by the same letter are not significantly different at 5\% level (Fisher's exact test).

\begin{tabular}{lcc}
\hline Crossing combination & $\begin{array}{c}\text { Percentage of host } \\
\text { eggs yielding } \\
\text { parasitoids }\end{array}$ & Mean sex ratio* \\
\hline Turkish $\times$ African & $95.6 \pm 3.14 \mathrm{a}$ & $0.28 \pm 0.08 \mathrm{a}$ \\
$\$$ Turkish $\times$ African & $94.0 \pm 4.09 \mathrm{a}$ & $0.28 \pm 0.10 \mathrm{a}$ \\
\hline
\end{tabular}

*values expressed as percent males

Crossing experiments. Cross mating tests were carried out to confirm that two strains belonged to the same species. Virgin pairs, $1-2 \mathrm{~d}$ old, of both combinations were confined for $\approx 48 \mathrm{~h}$ in a test tube to allow copulation. Individual females were then placed in a tube with approximately 20 unparasitised $S$. nonagrioides eggs. After $24-\mathrm{h}$ the egg masses were removed and individually stored until offspring emerged, when their sex was recorded. The crosses were evaluated indirectly by counting the pairs that produced female offspring, as this species has haplodiploid sex determination. Each cross was replicated 3 times.

Development, progeny production and sex ratio. The longevity and fecundity of the two T. busseolae strains were measured by confining each newly emerged female $(<24 \mathrm{~h}$ old) with $\approx 100$ one-day-old eggs. These females have been previously confined with males for few hours. Host eggs were removed and replaced with fresh eggs every $24 \mathrm{~h}$ until the death of the females. The eggs that were removed daily were incubated in vials at 18 -h photophase, $26 \pm 1{ }^{\circ} \mathrm{C}$, and $65 \pm 5 \% \mathrm{RH}$ until parasitoid emergence. Longevity, fecundity and the duration of the oviposition period of the adult parasitoids and the sex ratio of the emerging progeny were recorded.

Behavioural comparisons. Freshly emerged $T$. busseolae females were kept for $\approx 24 \mathrm{~h}$ with males, then they were individually isolated and supplied with a drop of honey solution. The females used in this experiment were $2-3 \mathrm{~d}$ old, had not oviposited previously, or been in contact with the host or its body, and were used only once. The olfactometer consisted of a round arena (30-mm inside diameter, 5- $\mathrm{mm}$ height), made of transparent Plexiglas and sandwiched between two glass sheets $(15 \times 20 \mathrm{~cm})$. Four $3-\mathrm{mm}$ holes were drilled at right angles in the wall of the arena. The behaviour of each released female was recorded by means of a computer vision system, EthoVision (Noldus Information Technology, version 1.97 ), at $\approx 8$ images $/ \mathrm{s}$, and the same software was used to process the data (Colazza et al., 1997). Observations were made between 10:00 and 15:00 h
TABLE 3. Comparison of the path parameters of two strains of $T$. busseolae. Number of replicates $=28$. Results are given as means and standard deviation.

\begin{tabular}{lccc}
\hline Path parametres & African strain & Turkish strain & $P^{*}$ \\
\hline $\begin{array}{l}\text { Linear speed } \\
(\mathrm{cm} / \mathrm{s})\end{array}$ & $0.51 \pm 0.04$ & $0.36 \pm 0.14$ & $<0.0001$ \\
$\begin{array}{l}\text { Angular speed } \\
\text { (degrees } / \mathrm{s})\end{array}$ & $82.28 \pm 6.50$ & $96.19 \pm 14.01$ & $<0.0001$ \\
$\begin{array}{l}\text { Turning rate } \\
\text { (degrees } / \mathrm{cm})\end{array}$ & $11.85 \pm 1.08$ & $16.63 \pm 3.36$ & $<0.0001$ \\
\hline
\end{tabular}

* Fisher's exact test

at $\approx 26^{\circ} \mathrm{C}$, and after each trial, the arena was cleaned with hexane, washed with laboratory detergent and allowed to dry for at least $24 \mathrm{~h}$.

Each female used was allowed $\approx 30 \mathrm{~min}$ to adapt to the arena, after which its locomotory patterns were recorded for $3 \mathrm{~min}$ using the computer vision system.

In order to evaluate the parasitoid response to the synthetic host pheromone, both the entrance and the exit of the air from the arena was controlled by a peristaltic pump (Ismatec, BVK MS-CA8/6). Two separate odour fields were created in the arena by pumping air at a flow rate of $18 \mathrm{ml} / \mathrm{min}$ in through two adjacent holes and simultaneously withdrawing air from the two opposite holes. The separation of the two odour field was tested using smoke tubes (AUER, Rauchröhrchen). Before entering the arena, the air was filtered and then humidified by passing through $250 \mathrm{ml}$ of water. For the first $90 \mathrm{~s}$ (control period), clean air entered through both holes. During the next $90 \mathrm{~s}$ (test period), one of the two entry holes was connected to a $350 \mathrm{ml}$ glass vial sealed with a Teflon containing rubber septum impregnated with the synthetic sex pheromone of $S$. nonagrioides (Colazza et al., 1997). A continuous air stream passed through the vial containing the odour even when it was not connected to the arena in order to keep the concentration of the host sex pheromone constant. A new rubber septum containing the sex pheromone was used for every five tests.

In order to evaluate the response of the parasitoid to host body scales, $10.7 \pm 3.8$ body scale $/ \mathrm{mm}^{2}$, the amount left by a moth at an oviposition site, were put into a circular zone (15 $\mathrm{mm}$ in diameter) in the center of the arena. Scales were brushed from ovipositing female moths and the density estimated by counting the scales in 5 randomly-selected sub areas. The path of the parasitoid in the arena was recorded with the videotracking device for 5 minutes after it first entered the circular zone.

TABLE 2. Comparison of female longevity and reproductive characteristics of two strains of $T$. busseolae. Results are given as means and standard deviation. $N=$ number of replicates. Values in a column followed by the same letter are not significantly different at $5 \%$ level (Fisher's exact test).

\begin{tabular}{|c|c|c|c|c|c|c|}
\hline \multirow{2}{*}{ Strain } & \multirow{2}{*}{ Longevity (day) } & \multirow{2}{*}{$\begin{array}{l}\text { Duration of ovi- } \\
\text { position (day) }\end{array}$} & \multicolumn{4}{|c|}{ Number of offspring } \\
\hline & & & Females & Males & Sex-ratio * & Total progeny \\
\hline African & $6.00 \pm 5.8 \mathrm{a}$ & $4.78 \pm 5.52 \mathrm{a}$ & $65.00 \pm 25.55 \mathrm{a}$ & $30.66 \pm 18.25 \mathrm{a}$ & $0.29 \pm 0.09 \mathrm{a}$ & $91.33 \pm 39.55 \mathrm{a}$ \\
\hline$N$ & 14 & 15 & $15^{* *}$ & $15 * *$ & $15 * *$ & 16 \\
\hline Turkish & $7.18 \pm 4.19 \mathrm{a}$ & $3.00 \pm 2.09 \mathrm{a}$ & $56.00 \pm 21.20 \mathrm{a}$ & $37.41 \pm 27.47 \mathrm{a}$ & $0.30 \pm 0.19 \mathrm{a}$ & $76.94 \pm 34.43 \mathrm{a}$ \\
\hline$N$ & 16 & 17 & $12 * *$ & $12 * *$ & $12^{* *}$ & 17 \\
\hline
\end{tabular}

\footnotetext{
* values expressed as percent males

** one female (African strain) and five females (Turkish strain) produced only male progeny
} 

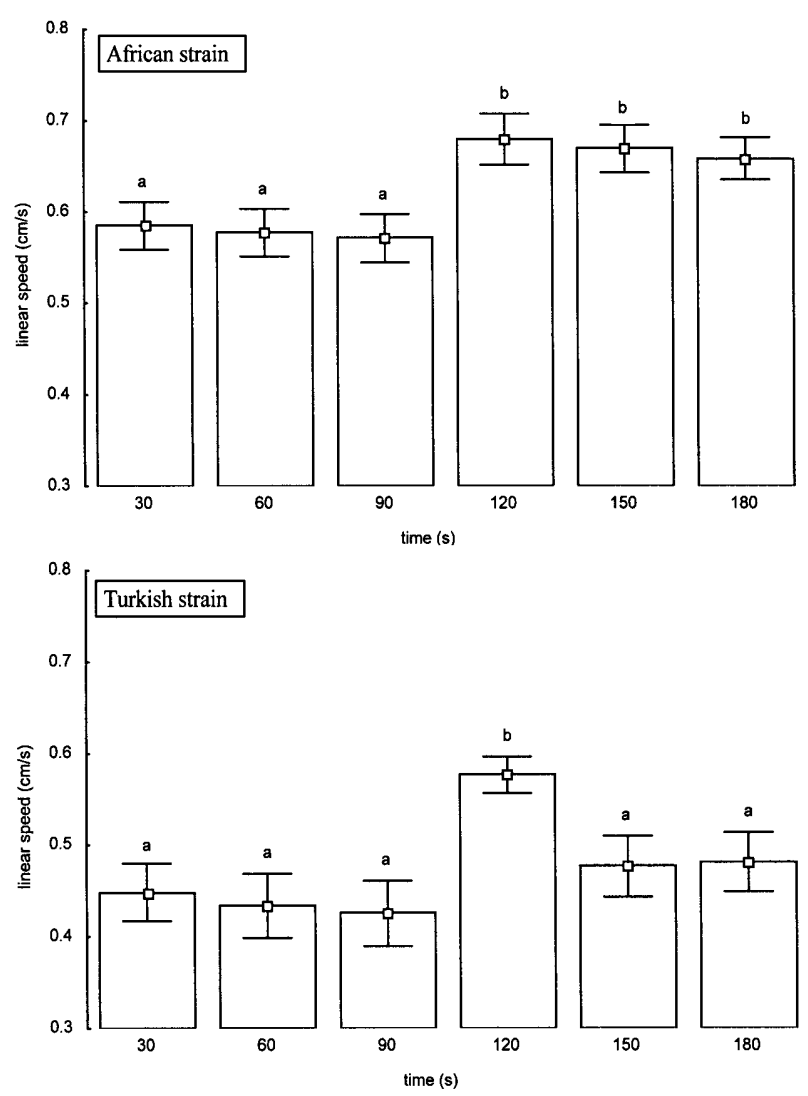

Fig. 1. Linear speed of females of T. busseolae of the African and Turkish strains calculated every 30 -seconds. During the first $90 \mathrm{~s}$ (control period) only clean air was present in the arena, in the next 90 s the synthetic sex pheromone of $S$. nonagrioides (test period) was introduced via one of the entry holes. Bars indicate mean $\pm \mathrm{SE}$. Each mean is based on 31 observations (African strain) and 32 observations (Turkish strain). Different letters above bars indicate significantly different means (Tukey test, $\alpha=0.05$ ).

Statistical analysis. Percentages were arcsine-transformed before analysis. Statistical analysis was performed by analysis of variance (ANOVA) or by Fisher's exact probability test, pairwise tests were performed by choosing appropriate contrast. All the corresponding computation was done with Statistica (Software Package release 5.1) (StatSoft, 1997).

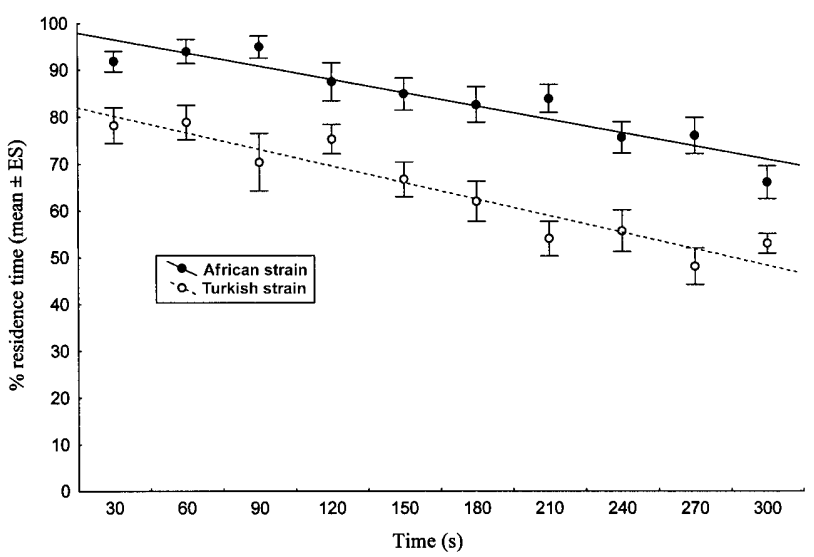

Fig. 2. Mean residence times ( \pm SE) calculated every 30 s and regression line for both the African and Turkish strains of $T$. busseolae.

\section{RESULTS}

Crossing experiments. All crosses produced mixed broods of males and females (Table 1) implying that the reciprocal crosses between the African and the Turkish strain resulted in successful mating, as $T$. busseolae is arrhenotokous. The percentage of eggs that yielded parasitoids and the sex ratios were comparable to those produced by intra-strain crosses (cf. Table 2). Thus, in the laboratory, the two strains were reproductively compatible.

Development, progeny production and sex ratio. The two strains did not differ significantly in either the longevity of their females or their oviposition period (Table 2 ). They were short-lived, $\approx 6-7 \mathrm{~d}$ on average and began ovipositing on the day of emergence. The pattern of egg laying was similar in both strains. Most parasitoid eggs were laid during the first three days of adult life, followed by a steady decline. In both strains the oviposition period lasted $\approx 3-5$ days (Table 2 ). No statistically significant differences were found in the production of offspring, as in the sex ratio of the offspring, about one third of which were males.

Behavioural comparison. After introduction into the arenas, females of both strains usually searched the arena in an apparently random pattern. The search patterns of the two strains in absence of host stimuli were significantly different. The African wasps walked significantly faster and straighter than the Turkish strain ( $t$-test, $P<$ 0.0001 for all the parameters, i.e. linear speed, angular speed and turning bias) (Table 3 ).

The influence of the host sex pheromone on the parasitoid's searching behaviour is reported in Table 4. During the first $90 \mathrm{~s}$ (control period), the females of both strains explored the entire arena. During the second $90 \mathrm{~s}$ (test period), the females spent most of their time in the zone with the host sex pheromone, significantly increased only their linear speed ( $t$-test, $P<0.01$ ), but did not change their walking pattern ( $t$-test, $P>0.05$ for both angular speed and turning bias). Over the $3 \mathrm{~min}$ of the recording, the mean linear speed of the strains differed $(\mathrm{df}=5 ; F=$ 7.43; $P<0.00001$; ANOVA; for African strain and $\mathrm{df}=$ 5; $F=5.42 ; P<0.0001$; ANOVA; for Turkish strain) (Fig. 1). In particular, the African strain showed an increase in walking speed in the test period, whereas the Turkish strain only showed an increment in walking speed in the first $30 \mathrm{~s}$ of the test period (Fig. 1).

Both strains responded to the body scales of $S$. nonagrioides females. Once having entered the scalecontaminated area, females remained stationary and drummed the surface with their antennae, searched the immediate area intensively turning back when they moved out of the treated area. These responses were associated with changes in the normal walking behaviour. The kinetic reaction parameters are summarized in Table 5. Females in contact with the treated area showed a reversed orthokinesis and an increased klinokinesis, e.g. their linear speed decreased significantly ( $t$-test, $P<$ $0.0001)$, while both the angular speed and turning bias increased significantly ( $t$-test, $P<0.0001$ ), which indi- 
TABLE 4. Comparison of the path parameters of two strains of $T$. busseolae before (control period) and after (test period) exposure of the females to the synthetic sex pheromone of $S$. nonagrioides blend. Results are given as means and standard deviation. $N=$ number of replicates.

\begin{tabular}{llrrrr}
\hline Path parametres & T. busseolae strain & Control period & Test period & $P^{*}$ \\
\hline & African strain & & & & \\
Linear speed (cm/s) & $(N=31)$ & $0.58 \pm 0.14$ & $0.66 \pm 0.13$ & $<0.01$ \\
Angular speed (degrees/s) & & $71.62 \pm 20.79$ & $68.20 \pm 19.75$ & $\mathrm{~ns}$ \\
Turning rate (degrees/cm) & & $21.39 \pm 8.28$ & $19.71 \pm 6.13$ & $\mathrm{~ns}$ \\
& Turkish strain & & & & \\
Linear speed (cm/s) & $(\mathrm{N}=32)$ & $0.43 \pm 0.17$ & $0.48 \pm 0.15$ & $<0.05$ \\
Angular speed (degrees/s) & & $63.19 \pm 26.87$ & $59.02 \pm 15.43$ & $\mathrm{~ns}$ \\
Turning rate (degrees/cm) & & $19.87 \pm 11.07$ & $17.46 \pm 4.96$ & $\mathrm{~ns}$ \\
\hline
\end{tabular}

* Fisher's exact test (paired test).

cates that host body scales are an arrestant stimulus for wasp's females. The times spent by each strain of $T$. busseolae in the area contaminated with host scales, calculated every $30 \mathrm{~s}$, during the $300 \mathrm{~s}$ of recording, are reported in Fig. 2. The residence times of the two strains decreased linearly over time (linearity test, $F=0.65$, ns, and $F=1.02$, ns; slopes, -0.49 and $-0.51, P<0.05$ for African and Turkish strain, respectively); i.e. the responses elicited by host scales diminished with stimulus repetition. The main difference between the two strains is that the residence time of the Turkish strain was always lower than that of the African strain (Fig. 2).

\section{DISCUSSION AND CONCLUSIONS}

Intraspecific variability in biological or behavioural traits of entomophagous parasitoids is important for their efficacy in biological control (Ruberson et al., 1989). Moreover, the definition of the differences between strains is important in biosystematics for effective integration into pest management (Lewis et al., 1990).

Our crossing experiments showed that the two strains of $T$. busseolae are reproductively compatible in the laboratory, as they produce viable offspring. This biological evidence need to be corroborated by a molecular study. They have been successfully applied to taxonomic studies (Post et al., 1992). An important genetic marker used to separate species and strains is ribosomal DNA (rDNA). In particular, the ITS.2 (5.8S-28S ribosomal DNA Internal Transcribed Spacer) is a very useful gene for distinguishing differences between insect species (Turbeville et al., 1991). A recent study of the strains of $T$. busseolae using these techniques revealed that the compared sequences scored 474 out of 523, the sizes of PCR were $513 b p$ for the African strain and $496 \mathrm{bp}$ for the Turkish strain (Rosi M.C. \& Hu Jianguo, not published). This divergence of $\approx 3 \%$ at this locus does not indicate that these two strains are different species. The data reported here on the bionomics of $T$. busseolae are generally in accordance with those of the strain from Greece (Laudonia et al., 1991). Chabi Olaye et al. (1997) found that females of the same geographic origin as our African strain lived 2-times longer at a similar temperature.

In the absence of host cues, which may stimulate undirected (kineses) and/or directed (taxes) responses, the area searched by a parasitoid is largest when it moves fast and straight (Bell, 1991). Bigler et al. (1988) found that differences in the speed of movement of a number of strains of Trichogramma maidis Pintoureau \& Voege. in the laboratory corresponded with their performance in the field. Females of T. busseolae do much of their searching for eggs on the plant by walking. Therefore, in the "random search" mode, i.e., when neither the host's sex pheromone nor its body scales have been detected, the search pattern of females of the African strain may be more effective.

When searching for host's location, T. busseolae females react to the host's sex pheromone, spending more time in areas where $S$. nonagrioides is calling (Colazza et al., 1997). The same behaviour was observed in this study. Both strains responded to the host's sex pheromone, but the females of the African strain responded for longer. This increase in searching activity may give the

TABLE 5. Comparison of the path parameters of two strains of $T$. busseolae when walking outside and inside an area contaminated with $S$. nonagrioides wing scales. $N=$ number of replicates. Results are given as means and standard deviation.

\begin{tabular}{llccc}
\hline Path parameters & T. busseolae strain & Outside kairomone area & Inside kairomone area & $P^{*}$ \\
\hline & African strain & & & \\
Linear speed $(\mathrm{cm} / \mathrm{s})$ & $(N=22)$ & $0.39 \pm 0.11$ & $0.19 \pm 0.07$ & $<0.0001$ \\
Angular speed $($ degrees/s) & & $85.30 \pm 18.94$ & $103.95 \pm 18.36$ & $<0.0001$ \\
Turning rate (degrees/cm) & & $26.46 \pm 6.80$ & $37.38 \pm 7.11$ & $<0.0001$ \\
& Turkish strain & & & $<.22 \pm 0.09$ \\
Linear speed $(\mathrm{cm} / \mathrm{s})$ & $(N=22)$ & $0.35 \pm 0.10$ & $86.42 \pm 15.10$ & $<0.0001$ \\
Angular speed $($ degrees/s) & & $69.94 \pm 16.25$ & $32.35 \pm 6.70$ & $<0.001$ \\
Turning rate $($ degrees $/ \mathrm{cm})$ & & $21.77 \pm 5.74$ & & \\
\hline
\end{tabular}

* Fisher's exact test (paired test). 
African strain a better chance of finding eggs or encountering other cues spatially correlated with host eggs.

Scales left by ovipositing females act as a contact kairomone and induce a host-seeking response in egg parasitoids belonging to the family Trichogrammatidae and Scelionidae (see for review Godfray, 1994). In general, scales are a valuable cue indicating the presence of host adults, however, their reliability as an indication of the presence of host eggs is closely related to the oviposition behaviour of the host. $S$. nonagrioides egg masses are concealed between a leaf blade and the stem, and in the field, $85 \%(n=14)$ of these egg masses were associated with patches of scales (personal observations). Therefore, the strong response of the African strain to remain in or around areas contaminated with scales should increase its probability of locating eggs. Behavioural variation may exist because individuals differ genetically. Recent observations on genetic variability in $T$. busseolae have revealed a genetic component in the arrestment response to the host scales in the African strain (Colazza, Salerno, Rosi \& Wajnberg, not published), and, in the Turkish strain, in the residence time on host egg masses (Wajnberg et al., 1999). This indicates that there is a genetic basis to the variability in the responses shown by the foraging females to the stimuli, which might influence the dynamics of host-parasitoid interactions.

Our data show that the African strain is the most effective in terms of host exploitation. However, correlation of these behavioural differences with their effectiveness in the field must be checked by specific field experiments. Such studies might provide a means of recognizing traits essential for the success or failure of a natural enemy. Currently, field experiments on $T$. busseolae are being planned (Conti, Salerno, Nobili \& Bin, personal communication) and the results will hopefully provide an answer as to which strain is the most effective in the field?

ACKNOWLEDGEMENTS. We thank S. Kornosor (University of Çukurova, Adana, Turkey) for the Turkish strain of $T$. busseolae, and F. Schulthess (International Institute of Tropical Agriculture, Cotonou, Republic of Benin) for the African strain of $T$. busseolae. We are indebted to G. Salerno (University of Perugia) for his help with the crossing experiments.

\section{REFERENCES}

AleXANDRi M.P. \& Tsitsipis J.A. 1990: Influence of the egg parasitoid Platytelenomus busseolae (Hym.: Scelionidae) on the population of Sesamia nonagrioides (Lep.: Noctuidae) in Central Greece. Entomophaga 35: 61-70.

BELL W.J. 1991: Searching Behaviour. The Behavioural Ecology of Finding Resources. Chapman \& Hall, London, $358 \mathrm{pp}$.

Bigler F., Bieri M., Fritschy A. \& Sedpel K. 1988: Variation in locomotion between laboratory strains of Trichogramma maidis and its impact on parasitism of eggs of Ostrinia nubilalis in the field. Entomol. Exp. Appl. 49: 283-290.

Chabi Olaye A., Schulthess F., Shanower T.G. \& BosquePÉrez N.A. 1997: Factors influencing the developmental rates and reproductive potentials of Telenomus busseolae (Ghan) (Hym.: Scelionidae), an egg parasitoid of Sesamia calamistis Hampson (Lep.: Noctuidae). Biol. Contr. 8: 15-21.
Colazza S., Rosi M.C. \& Clemente A. 1997: Response of the egg parasitoid Telenomus busseolae to sex pheromone of Sesamia nonagrioides. J. Chem. Ecol. 23 : 2437-2444.

DiEHL S.R. \& Bush G.L. 1984: An evolutionary and applied perspective of insect biotypes. Annu. Rev. Entomol. 29: 471-504.

Fantinou A.A., Alexandri M.P. \& Tsitsipis J.A. 1998: Adult emergence rhythm of the egg-parasitoid Telenomus busseolae. BioControl 43: 141-151.

Giacometti R. 1995: Rearing of Sesamia nonagrioides Lefevre on meridic diet (Lepidoptera Noctuidae). REDIA 78: 19-27.

Godfray H.C.J. 1994: Parasitoids: Behavioral and Evolutionary Ecology. Princeton University Press, Princeton, 473 $\mathrm{pp}$.

Gonzalez D., Gordh G., Thompson S.N. \& Adler J. 1979: Biotype discrimination and its importance to biological control. In Hoy M.A. \& McKelvey J.J. (eds): Genetics in Relation to Insects Management. New York, Rockefeller Foundation, pp. $129-136$.

Kornosor S., Sertkaya E. \& Özpinar A. 1994: Distribution of the egg parasitoid Platytelenomus busseolae (Gahan) (Hym.: Scelionidae) and its effect on the population of Sesamia nonagrioides Lef. (Lep.: Noctuidae) in the Mediterranean region of Turkey. In E. Wajnberg (ed.): Trichogramma and Other Egg Parasitoids. 4th International Symposium, Les Colloques de INRA, Paris nº73, pp. 193-199.

LaUdonia S., Viggiani G. \& Rotundo G. 1991: Dati morfobiologici sul Telenomus busseolae Gahan (Hymenoptera: Scelionidae), ooparassitoide di Sesamia nonagrioides (Lefevre) (Lepidoptera: Noctuidae) introdotto in Italia. Boll. Lab. Entomol. Agr. Filippo Silvestri 48: 125-136.

Lewis W.J., Vet L.E.M., Tumlison J.H., van Lenteren J.C. \& PAPAJ D.R. 1990: Variation in parasitoid foraging behaviour: essential element of a sound biological control theory. Envir. Entomol. 19: 1183-1193.

MoYAl P. 1998: Infestation patterns and parasitism of the maize stalk borer, Busseola fusca (Fulle) (Lepidoptera: Noctuidae), in the Ivory Coast. Afr. Entomol. 6: 289-296.

NuCIFORA A. 1966: Appunti sulla biologia di Sesamia nonagrioides (Lef.) in Sicilia. Tecnica Agricola 5: 395-419.

Polaszek A., Uberu J.A. \& Bosque-Perez N.A. 1993: Taxonomy of the Telenomus busseolae species-complex (Hymenoptera: Scelionidae) egg parasitoids of cereal stem borers (Lepidoptera: Noctuidae, Pyralidae). Bull. Entomol. Res. 83: 221-226.

Post R.J., Flook P.K. \& Wilson M.D. 1992: DNA analysis in relation to insects taxonomy, evolution and identification. In Crapton J.M. \& Eggleston P. (eds): Insect Molecular Science. Royal Entomological Society and Academic Press, London, pp. 21-34.

Prota R. 1965: Osservazioni sull'etologia di Sesamia nonagrioides (Lefevre) in Sardegna. Studi Sass. Sez. III 13: 336-360.

Rotundo G., Tonini C., CapizzI A. \& Main S. 1985: Il feromone sessuale di Sesamia nonagrioides lef. (Lepidoptera: Noctuidae). Boll. Lab. Entomol. Agr. Filippo Silvestri 42: 191-206.

Rúberson J.R., TAurber M.J. \& Tauber C.A. 1989: Intraspecific variability in hymenopteran parasitoids: comparative studies of two biotypes of the egg parasitoid Edovum puttleri (Hymenoptera: Eulophidae). J. Kansas Entomol. Soc. 62: 189-202.

SÉtamou M. \& Schulthess F. 1995: The influence of egg parasitoids belonging to the Telenomus busseolae (Hymenoptera: Scelionidae) species complex on Sesamia calamistis (Lepidoptera: Noctuidae) populations in maize fields in southern Benin. Biocontr. Sci. Technol. 5: 69-81. 
STATSOFT 1997: Statistica for Windows version 5.1 statistical software: user's manual, module non-parametric statistics \& distribution fitting. StatSoft, Inc.

Turbeville J.M., Pfeifer D.M., Field K.G. \& Raff R.A. 1991 The phylogenetic status of arthropods as inferred from $18 \mathrm{~S}$ rRNA sequences. Mol. Biol. Evol. 8: 669-686.
WAJnBerg E., Rosi M.C. \& ColazZa S. 1999: Genetic variation in patch time allocation in a parasitic wasp. J. Animal Ecol. 68: $121-133$.

Received May 29, 2000; revised September 25, 2000; accepted October 31, 2000 